\title{
Targeting CD8 T-cell metabolism in transplantation
}

\author{
Michelle Yap ${ }^{1,2}$, Sophie Brouard ${ }^{1,3,4,5}$, Claire Pecqueur ${ }^{2,6}$ and Nicolas Degauque ${ }^{1,3 *}$ \\ ${ }^{1}$ UMR 1064, INSERM, Nantes, France, ${ }^{2}$ Faculté de Médecine, Université de Nantes, Nantes, France, ${ }^{3} \mathrm{CHU}$ de Nantes, \\ ITUN, Nantes, France, ${ }^{4} \mathrm{ClC}$ Biothérapie, Nantes, France, ${ }^{5} \mathrm{CHU}$ Nantes, CRB, Nantes, France, ${ }^{6}$ UMR 892, INSERM, \\ Nantes, France
}

Infiltration of effector CD8 T cells plays a major role in allograft rejection, and increases in memory and terminally differentiated effector memory CD8 T cells are associated with long-term allograft dysfunction. Alternatively, CD8 regulatory T cells suppress the inflammatory responses of effector lymphocytes and induce allograft tolerance in animal models. Recently, there has been a renewed interest in the field of immunometabolics and its important role in CD8 function and differentiation. The purpose of this review is to highlight the key metabolic pathways involved in CD8 T cells and to discuss how manipulating these metabolic pathways could lead to new immunosuppressive strategies for the transplantation field.

Keywords: CD8 lymphocytes, transplantation, metabolism, glycolysis, mitochondria, regulation, therapeutics

OPEN ACCESS

Edited by:

Chiara Bonini,

San Raffaele Scientific Institute, Italy

Reviewed by:

Luca Gattinoni,

National Cancer Institute, USA

Nicoletta Cieri,

University of Milan, Italy

*Correspondence:

Nicolas Degauque nicolas.degauque@univ-nantes.fr

Specialty section:

This article was submitted to Alloimmunity and Transplantation,

a section of the journal

Frontiers in Immunology

Received: 30 July 2015

Accepted: 12 October 2015

Published: 23 October 2015

Citation:

Yap M, Brouard S, Pecqueur $C$ and Degauque N (2015) Targeting CD8 T-cell metabolism in transplantation.

Front. Immunol. 6:547.

doi: 10.3389/fimmu.2015.00547

\section{INTRODUCTION}

To efficiently protect mammalian against pathogen infection, the response of the adaptive T-cell immune system follows a three-step process: an initial phase of T-cell priming followed by a massive clonal expansion and differentiation, a contraction phase leading to the clearance of most effector cells, and the generation of memory immune T cells. Numerous subsets of memory CD8 T cells have been described with different functions and localization within the body. Seminal study by Sallusto et al. identified that isoform CD45RA and lymph node homing marker CCR7 allow the discrimination of naive and subsets of memory CD8 cells (central memory, CM; effector memory, EM; terminally differentiated effector memory cells, TEMRA) (1). The inclusion of additional markers, such as CD27, CD28, CD57, or TBET, can narrow down the identification of specific memory subsets to decipher their relative function during the recall response and to identify checkpoint regulating their differentiation and their survival (2). T-cell response to antigen stimulation and activating their effector functions are energetically demanding processes. Over the last decade, numerous reports have highlighted that the generation of effector and memory cells is not only regulated by the inflammatory milieu but also by metabolic processes.

In the 1920s, Otto Warburg observed that cancer cells consumed much higher amounts of glucose compared with normal cells and that cancer cells mainly utilize glycolysis over mitochondrial respiration, even in the presence of oxygen $(3,4)$. This metabolic strategy, termed the Warburg effect, has also been observed in activated lymphocytes (5-7). Despite being less efficient albeit rapid at producing ATP, the aerobic glycolysis enables cells to generate the biosynthetic precursors necessary to support rapid growth and proliferation as well as to maintain the redox balance (8). The renewed interest in the metabolic processes involved in T-cell biology has also revealed that evolutionary conserved pathways, such as the mammalian target of rapamycin (mTOR) pathway, are common to both immune responses and metabolism regulation (9). The goal of this review is to summarize the link between 
CD8 T-cell subsets and their metabolic adaptations and to evaluate how targeting this metabolic programming could be a new possible therapeutic treatment, with a special focus on transplantation.

\section{T CELL AND TRANSPLANT OUTCOME: KNOWN TARGETS THAT REQUIRED NEW THERAPEUTIC TOOLS}

Involvement of $\mathrm{T}$ lymphocytes in solid organ transplant rejection is a well-researched topic in the transplantation field; however, most of the research focuses on the various roles of the different CD4 lymphocyte subpopulations. Few investigate the role of CD8 cells in transplantation with a main focus on their cytotoxic and proinflammatory functions and how deleterious they are to longterm allograft health (10-13). In acute allograft rejection, infiltrating CD8 T cells play a major role in tubulitis and tissue necrosis. Cytotoxic molecules, such as perforin and granzyme-B, as well as proinflammatory cytokines, such as IFN $-\gamma$, secreted by CD8 T cells have been shown to contribute to the rejection response (14, 15). Furthermore, memory CD8 T cells have been shown to act as major barriers for transplant tolerance induction protocols (16, 17). Additionally, recent immunomonitoring research has shown that an increase in certain $\mathrm{CD} 8$ populations in transplant patients is associated with allograft rejection and loss. Elevated effector, memory, and TEMRA CD8 subsets in the peripheral circulation are associated with increased occurrence of acute and chronic allograft dysfunction (18-22). As a result, immunomodulation of the CD8 population is an important component for long-term allograft survival and targeting their specific metabolic processes could represent a new mean to foster graft survival.

There is budding interest into a small subpopulation of CD8 lymphocytes with regulatory and suppressive functions. While most of the research has been focused on $\mathrm{CD}_{4}{ }^{+} \mathrm{FOXP} 3^{+}$Tregs, there is growing interest in the other types of regulatory $\mathrm{T}$ cells, which include the CD8 Tregs (23-25). There have been several different nomenclatures proposed in the literature, which can be used to identify this subset of cells, a few examples being $\mathrm{CD} 8^{+} \mathrm{CD} 28^{-}, \mathrm{CD}^{+}{ }^{+} \mathrm{CD} 45 \mathrm{RC}^{\text {low }}$, and $\mathrm{CD} 8^{+} \mathrm{FOXP}^{+}(26-28) . \mathrm{CD} 8$ Treg populations have potent suppressive ability against effector lymphocytes and promote tolerant induction in rodent transplant models, thus making them an attractive target for promoting allograft survival $(23,24,28-30)$. Immunometabolic regulation of CD8 T cells could be used as a means to manipulate the CD8 T-cell immune function for effective immunosuppression. However, little is known regarding their metabolic adaptation during the induction and the expansion phases.

\section{CD8 T-CELL METABOLIC PROGRAMMING CHANGES ARE SPECIFIC TO CD8 SUBSETS AND FUNCTION}

\section{Metabolic Demands in Quiescent T Cells}

In resting state, naive $\mathrm{T}$ cells rely on oxidative phosphorylation (OXPHOS) to produce adenosine $5^{\prime}$-triphosphate (ATP) (31). This metabolic pathway is the most effective method to generate ATP by catabolizing metabolic intermediates derived from glucose, fatty acids, and amino acids. The low rate of energy metabolism needed by quiescent cells to maintain their housekeeping functions is instructed by cytokine-dependent signals and preferentially IL-7-mediated signals. Indeed, IL-7 is a crucial cytokine to sustain the homeostasis of naive cells and their survival and is also an important regulator of the glucose transporter GLUT-1 (32). The IL-7 receptor (IL-7R) is largely expressed in naive lymphocytes and downregulated when naive CD8 T cells differentiate into the effector phenotype. IL-7 causes activation of JAK1 and JAK3, which in turn activates STAT5 and the PI3K/AKT pathways (32-34). IL-7 allows a basal glucose metabolism, which has been shown to be essential for quiescent T-cell survival (32).

In addition to mitochondrial glucose oxidation, resting $\mathrm{T}$ cells generate energy through the $\beta$-oxidation of fatty acids and especially quiescent memory subsets (Figure 1A). Fatty acid oxidation (FAO) is integral to the development of memory T cells, and when FAO is impeded, the memory CD8 T-cell population is heavily affected $(35,36)$. Pearce et al. showed that mice which lack tumor necrosis receptor-associated factor 6 (TRAF6) cannot upregulate $\mathrm{FAO}$, and while these mice were able to mount a normal effector $\mathrm{CD} 8$ response, they were unable to form a $\mathrm{CD} 8$ memory population after bacterial infection (37). Additionally, TRAF6-deficient CD8 cells could not properly activate AMP-activated kinase (AMPK); however, metformin, an AMPK activator, was able to rescue FAO in the TRAF6-deficient CD8 cells and promote the development of the memory subset (37). Interestingly, the fatty acids used are not acquired from their external environment. Instead, FAO is supported in memory $\mathrm{T}$ cells by the synthesis of triacylglycerols (TAGs) from externally acquired glucose. IL-7 has been shown to upregulate the expression of glycerol channel aquaporin 9 (AQP9) and increased TAG synthesis in antigen-experienced CD8 T cells. The resulting TAGs are hydrolyzed by lysosomal acid lipase into free fatty acids for FAO $(36,38)$. The generation of potent CD8 memory $\mathrm{T}$ cells is also dependent on mTOR-related signaling since rapamycin, a mTOR inhibitor, promotes memory T-cell differentiation $(39,40)$. Rapamycin treatment during the CD8 expansion phase has been shown to increase the resulting quantity of CD8 memory cells; furthermore, rapamycin given during the contraction phase results in memory CD8 cells that are highly functional and can mount a better memory response $(39,41,42)$.

\section{Activation of CD8 T Cells Leads to Metabolic Reprogramming}

Proliferation and potent effector functions are an energetically demanding process that requires a metabolic adaptation in order to fulfill the needs of $\mathrm{T}$ cells. Upon activation, CD8 T cells reprogram their metabolism from OXPHOS to aerobic glycolysis and glutaminolysis (Figure 1B) (5). This glycolytic shift supports the rapid proliferation of activated lymphocytes not only in terms of energy requirement but also in terms of metabolic intermediates (43). These metabolic intermediates allow the biosynthesis of macromolecules essential for the massive cell growth and proliferation required as effector $\mathrm{CD} 8$ cells expand during the immune response. For example, these intermediates generated from the glycolytic pathway are used to generate nucleotides, amino acids, and lipids, which in turn will be used to synthesize nucleic acids, lipids, and proteins needed in order to duplicate the cellular biomass $(8,43)$. 

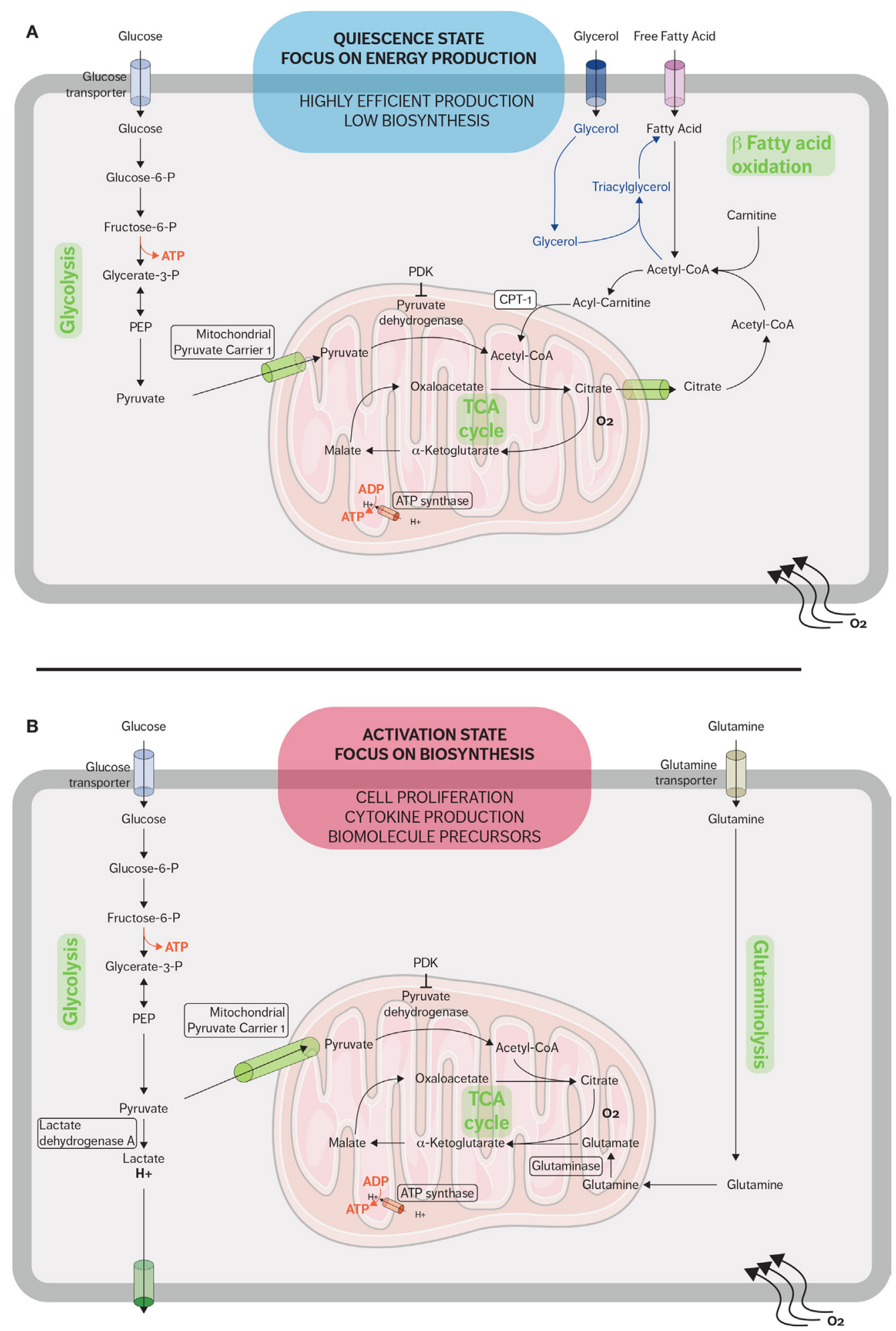

FIGURE 1 | Metabolic pathways used by CD8 T cells in quiescent and active states. (A) When in a quiescent state, naive CD8 T cells fulfill their energy needs mainly through aerobic glycolysis and mitochondrial respiration. Fatty acid oxidation plays an important role during the restriction phase when effector CD8 cells differentiate into memory CD8 cells and the immune system returns to a quiescent state. Memory $T$ cells synthesized fatty triacylglycerols to supply fatty acids for fatty acid oxidation. (B) When stimulated, effector CD8 T cells rapidly upregulate glycolysis and glutaminolysis because the activated cells require many of the metabolic intermediates for macromolecule biosynthesis. The metabolic adaptations sustain the rapid expansion of effector CD8 T cells and support the secretion of cytokines and cytotoxic molecules. 
T-cell activation requires two signals: one from the T-cell receptor (TCR) and the other from costimulatory receptors. TCR signaling alone is not sufficient for inducing major changes to the metabolic programming (44). The increased glucose metabolism seen in activated lymphocytes is due to CD28 costimulation signaling, which in turn activates the PI3K/AKT pathway (Figure 2) (44-46), leading to an increase of nutriment uptake, cell-surface expression, and function of glucose transporter. However, it is becoming apparent that there are specific metabolic adaptations dependent on the T-cell subset. Gubser et al. showed that the effector memory CD8 $\mathrm{T}$ cells are able to switch to glycolysis more rapidly as compared to naive CD8 T cells (47). Furthermore, effector memory CD8 T cells are able to sustain this higher glycolytic rate. Glycolysis has also been implicated in posttranscriptional control of cytokine secretion in activated lymphocytes. Glyceraldehyde-3-phosphate dehydrogenase (GAPDH) is an enzyme involved in the glycolytic process and has been shown to act as an mRNA-binding protein. Chang et al. demonstrated that interferon- $\gamma$ (IFN $\gamma$ ) secretion was suppressed in activated lymphocytes which were cultured in galactose and thus could not utilize the glycolytic pathway. The depression in the IFN $\gamma$ secretion is due to the binding of GAPDH to IFN $\gamma$ transcripts. Therefore, glycolysis in lymphocytes has a secondary role as a regulator of GAPDH binding of IFN $\gamma$ (48). The drastic diversion of energy generation from OXPHOS to aerobic glycolysis induced by T-cell activation may be oversimplified as a higher mitochondrial mass of memory CD8 $\mathrm{T}$ cells compared to naive CD8 T cells has been reported and linked to a higher enhancement of both OXPHOS and glycolysis in memory CD8 T cells (49).
In addition to increased glycolytic activity, activated T cells also upregulate glutamine metabolism (glutaminolysis). Glutamine, a common amino acid found in human plasma, can serve as an alternative source of energy. Activated lymphocytes require glutamine for cell proliferation and cytokine secretion, and CD28 costimulation enhances glutamine uptake and increases glutamine transporter expression $(50,51)$. Several metabolic TCA cycle intermediates, such as citrate, $\alpha$-ketoglutarate, and oxaloacetate, are crucial for proliferation as precursor for lipid and amino acids synthesis. Glutamine undergoes anaplerotic reaction to produce oxaloacetate and $\alpha$-ketoglutarate metabolism through glutamate. Glutaminolysis also replenishes NADPH pool, which is also needed by proliferating lymphocytes to support lipid and nucleotide biosynthesis as well as maintaining the redox balance $(51,52)$.

\section{METABOLIC TARGETS FOR IMMUNOMODULATING CD8 T CELLS}

There are two possible approaches to manipulating the metabolic programming of CD8 cells as a means of immunosuppression for transplantation. The first would be to target metabolic pathways that are involved in cytokine production and cytotoxic activity of effector and effector memory cells in order to shut down CD8 T cells' ability to cause damage to allografts (Figure 2). The other method would be to target metabolic pathways to enhance and promote the proliferation of CD8 Tregs, which will in turn cause a suppressive effect on the CD8 effector population, thus prolonging allograft half-life and possibly favoring tolerance induction.

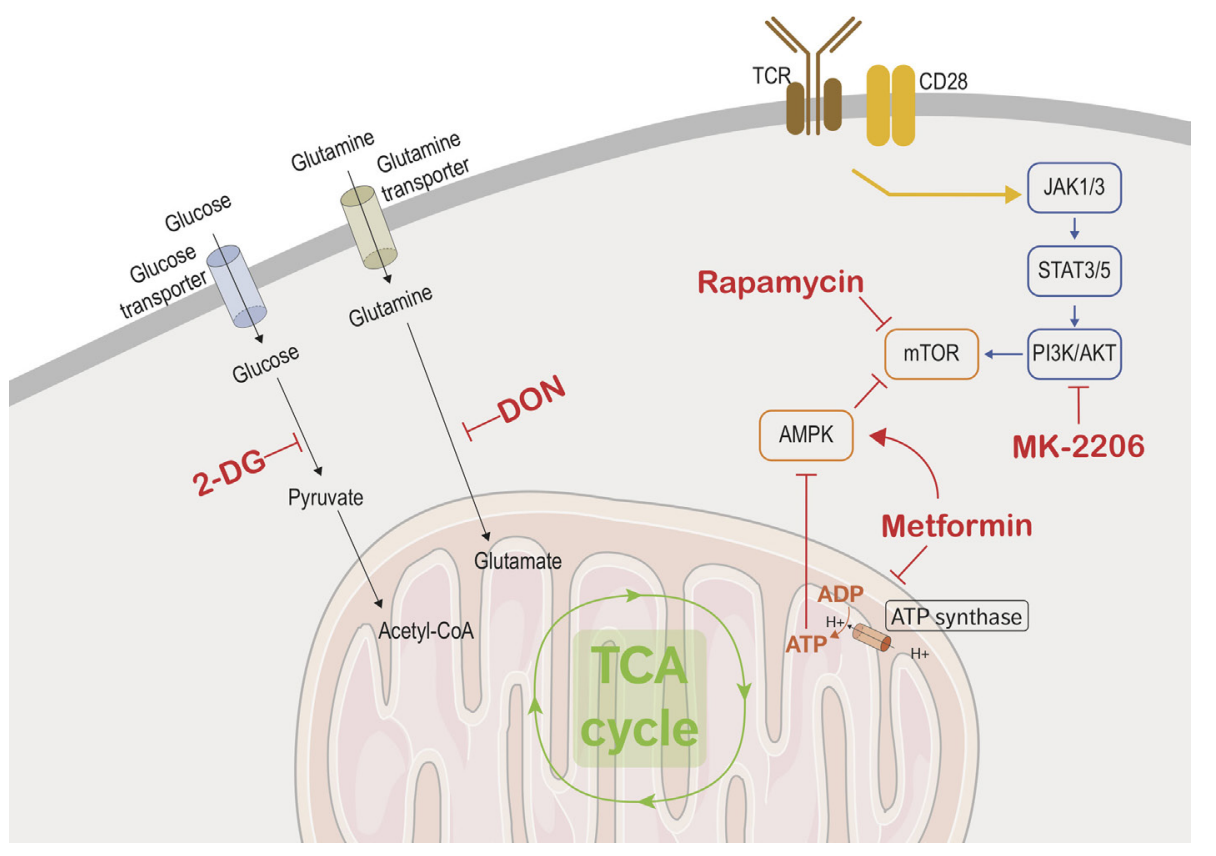

FIGURE 2 | Immunometabolic targets. This figure depicts the different metabolic and transcriptional pathways involved in the immunometabolic functions of CD8 T cells. Black arrows are used to show the transport of glucose and glutamine into the cells where they are metabolized. The yellow arrow represents the combined signaling of the TCR and CD28 which activates CD8 effector cells and triggers the metabolic adaptations in the effector cells. The blue arrows show the transcriptional used by activated CD8 T cells to upregulate mTOR, which controls cellular metabolism and growth. Red arrows show the promotion or suppression of therapeutic molecules on the various immunometabolic pathways. 


\section{Shutting Down the Warburg Effect in Effector CD8 T Cells}

As previously discussed, glycolysis and glutaminolysis are two key metabolic pathways that are imperative for proper CD8 effector function. Finding methods to interrupt these pathways in allograft infiltrating effector cells would be a mean stopping allograft rejection. 2-Deoxy-D-glucose (2-DG) is a glucose analog that inhibits glycolysis by blocking hexokinase function. Many studies showed the potent effect of 2-DG in inhibiting the cytotoxic function of effector CD8 cells $(47,53-55)$. In a similar fashion, blocking glutaminolysis with a glutamine antagonist such as 6-diazo-5-oxo-L-norleucine (DON) inhibits lymphocyte proliferation (56). Additionally, blocking glucose and glutamine transporters disrupt lymphocyte activation and affect memory differentiation (57-60).

Targeting major bioenergetic pathways seems at first glance a rather dangerous means to control an immune response and major side effects such as a massive toxicity to normal tissue is expected. Animal models and ongoing therapeutic use of metabolic interferences therapies prove that such strategy is safe and feasible. For instance, leflunomide and its active metabolite teriflunomide prevent de novo biosynthesis of pyrimidine and efficiently inhibit the development of EAE (61). In multiple sclerosis patients, teriflunomide, compared to placebo, significantly reduces relapse rates, disability progression (at the higher dose), and MRI evidence of disease activity (62). Interestingly, whereas a link with metabolism has not been established, leflunomide or analogs have also been shown to be effective in prolonging graft survival and even to induce tolerance in a model of heart allograft transplantation (63). Metabolic interferences have been mainly studied in the cancer field. Given the similarity of metabolic adaptation between cancer cells and activated $\mathrm{T}$ cells, immunometabolic regulation of CD8 T cells could be used as a means to manipulate the CD8 T-cell immune function for effective immunosuppression. However, the doses required to eradicate all malignant cells and those required to control auto-or alloreactive $\mathrm{T}$ cells might be radically different. Cancer therapy aims to eradicate all cancer cells, whereas transplant therapy aims to control alloreactive $\mathrm{T}$ cells. Given their effector nature, alloreactive T cells are likely to be characterized by a higher use of glycolysis as compared to quiescent $\mathrm{T}$ cells. The selective targeting of glycolysis processes will thus focus preferentially alloreactive and not quiescent (naive or memory) T cells.

\section{Targeting Transcriptional Regulators of Immunometabolism}

Since metabolic adaptation is required to support T-cell activation and function, nutrient availability or limitation will affect these processes. A recent publication has shown that adenosine monophosphate-activated protein kinase (AMPK) couples T-cell function to nutrient availability (64). AMPK is a serine-threonine kinase that is sensitive to energy levels and is activated during cellular stress. By sensing the AMP/ATP ratio, AMPK senses energy deficiency and favors pathways leading to ATP production while inhibiting ATP-consuming pathway. It increases catabolic processes and inhibits anabolic processes to increase
ATP production when activated. AMPK upregulates fatty acid $\beta$-oxidation by promoting the transfer of long-chain fatty acids into the mitochondria via carnitine palmitoyltransferase 1 (CPT1) (5). Metformin, a drug commonly used in diabetes treatment, blocks mitochondrial complex I, which has the downstream effect of promoting AMPK activity. Interestingly, metformin fosters memory CD8 T-cell differentiation in mice (37). In agreement with these results, it has been shown that autoreactive $\mathrm{T}$ cells can be efficiently controlled by the coadministration of 2-DG and metformin in a mouse model of systemic lupus erythematosus (SLE) (65). However, as meformin also inhibits OXPHOS, in vitro or in vivo administration is likely to have a broader target than solely the memory compartment.

The PI3K/AKT pathway is another key pathway that integrates immune stimulation and nutrient uptake (9). Blocking PI3K/ AKT pathway would therefore be another way to suppress the effector function of CD8 cells. The core kinases of this pathway are AKT, AMPK, and mTOR. An intimate positive and negative cross-regulation of these protein kinases has been shown and this topic has been covered in-depth in several publications $(5,6,9)$. AKT pathway is optimally activated by the coligation of TCR and CD28 and leads to the increase of glycolysis, via an increase of glucose uptake and the enhancement of rate-limiting glycolytic enzymes hexokinase and phosphofructokinase (66). Preventing activation of this pathway could be accomplished by inhibiting the costimulation signaling provided by CD28 or by directly inhibiting AKT activity. FR104, an anti-CD28 antagonist antibody, has been shown to prevent lymphocyte activation and proliferation in a murine model (67). Furthermore, this drug has been shown to be effective in reducing allograft rejection in both murine and non-human primate models of transplantation $(68,69)$. Another possible strategy would be to target AKT directly through the use of one of the AKT inhibitors currently in development (70). For example, AKT inhibitor MK-2206 treatment in a murine model increased the differentiation of naive CD8 cells into central memory CD8 cells and diminished terminal differentiation in the CD8 population (71). Additionally, AKT can be modulated upstream by inhibiting focal adhesion kinase (FAK), a wellestablished regulator of the PI3K/AKT pathway. Inhibiting FAK in Ewing sarcoma cells results in downregulation of both AKT and mTOR and impaired cell growth and colony formation (72, 73). Donor lymphocyte infusions following allogeneic stem cell transplantation are performed to enhance the graft-versus-tumor (GVT) effect, and minor histocompatibility antigen (MiHA)specific CD8 T cells play an important role in this GVT response. It has been hypothesized that adoptive MiHA-specific CD8 T-cell transfer would lead to a more efficacious GVT response while also minimized graft-versus-host disease (GVHD), a harmful effect which is also observed in allogeneic stem cell transplant patients. AKT signal inhibition during ex vivo priming of naive precursor cells resulted in the generation of stem cell-like MiHA-specific CD8 T cells. Additionally, these cells have a superior proliferation capacity and antitumor effects in a murine model (74). While clinical research on these developmental AKT inhibitors has been mainly focused on the field of oncology and allogeneic stem cell transplantation, there could be possible use for them in the solid organ transplantation field. 


\section{Boosting Treg Populations with Metabolic Programming}

In the field of CD4 Tregs, there has been a lot of progress in finding viable ways to use them in clinical practices. Several clinical trials are currently in progress to evaluate the safety and efficacy of adoptive transfer of CD4 Tregs in allograft transplant recipients (75). However, studies concerning CD8 Tregs are at more exploratory stages.

Rapamycin is an antifungal macrolide that is produced by bacteria discovered on Easter Island which targets and inhibits mTOR and is already used as a part of immunosuppressive regimens in transplantation. mTOR is a serine/threonine kinase that regulates cell survival, growth, and energy metabolism. mTOR can form two distinct complexes, mTOR complex 1 (mTORC1), which is rapamycin sensitive, and mTOR complex 2 (mTORC2), which is rapamycin insensitive and much less studied compared to mTORC1 $(41,76-79)$. mTORC1 is the master regulator of cell growth and metabolism and can be activated through either PI3K or AKT signaling. Upon activation, mTORC1 promotes ribosome biogenesis and increases protein translation and synthesis (6, 78, 79). mTORC1 also promotes lipid biosynthesis and regulates mitochondrial metabolism and biogenesis through sterol regulatory element-binding proteins (SREBP) which are involved in positively regulating lipid homeostasis $(80,81)$. Rapamycin targets and inhibits mTOR activity, thus interfering with G1 phase cell cycle activity and inhibits interleukin-2 (IL-2)-driven proliferation in Tlymphocytes. This leads to a potent immunosuppressive effect. Consequently, mTOR inhibitors have been adopted into use as a part of immunosuppressive regimens in solid organ transplantation $(82,83)$. In addition to the immunosuppressive effects of rapamycin, it has also been shown to induce the preferential growth of $\mathrm{CD}^{+}{ }^{+} \mathrm{CD} 25^{+} \mathrm{FOXP}^{+}$Tregs in vitro (84). Evidence is emerging that rapamycin treatment in vitro can also induce $\mathrm{CD} 8^{+} \mathrm{CD} 28^{-}$Tregs in murine models (85), indicating that adoptive transfer strategies to induce allograft tolerance that are currently under investigation for CD4 Tregs could potentially be adjusted for CD8 Tregs.

Another immunosuppressive drug that has been shown to be able to induce preferential expansion of CD8 Tregs in vitro is CTLA-4-Ig belatacept, a recently approved drug for transplant immunosuppression treatment (86). A CTLA-4 antagonist would affect the metabolic function of effector CD8 cells by blocking

\section{REFERENCES}

1. Sallusto F, Lenig D, Förster R, Lipp M, Lanzavecchia A. Two subsets of memory $\mathrm{T}$ lymphocytes with distinct homing potentials and effector functions. Nature (1999) 401:708-12. doi:10.1038/44385

2. Appay V, van Lier RA, Sallusto F, Roederer M. Phenotype and function of human T lymphocyte subsets: consensus and issues. Cytometry A (2008) 73:975-83. doi:10.1002/cyto.a.20643

3. Chen X, Yanrong Q, Wu S. The Warburg effect: evolving interpretations of an established concept. Free Radic Biol Med (2015) 79:253-63. doi:10.1016/j. freeradbiomed.2014.08.027

4. Warburg OH. The chemical constitution of respiration ferment. Science (1928) 68:437-43. doi:10.1007/s11999-010-1534-y

5. MacIver NJ, Michalek RD, Rathmell JC. Metabolic regulation of $\mathrm{T}$ lymphocytes. Annu Rev Immunol (2013) 31:259-83. doi:10.1146/ annurev-immunol-032712-095956
CD28 costimulation signaling, which has the downstream effects of impeding AKT activation and downregulating glucose and glutamine uptake. Additionally, Barbon et al. showed that by first alloanergizing human PBMCs with belatacept and then allostimulating the cells caused an increase in the frequency of $\mathrm{CD} 8^{+} \mathrm{CD} 28^{-} \mathrm{T}$ cells. Furthermore, repeated rounds of allorestimulation after alloanergization would continue to expand the $\mathrm{CD} 8^{+} \mathrm{CD} 28^{-}$Tregs, which were able to suppress the proliferation of CD4 T cells in a dose-dependent manner (86). Additionally, Barbon et al. reported on three hematopoietic stem cell transplant recipients with a marked increase in blood circulating $\mathrm{CD} 8^{+} \mathrm{CD} 28^{-} \mathrm{T}$ cells between days 20 and 40 post-transplantation (86). While these findings are still preliminary, it is promising evidence that CD8 Tregs could play a future role in controlling allograft rejection.

\section{CONCLUSION}

When CD8 T cells go from a quiescent to an activated state, there are also major alterations to their metabolic programming. Upregulation of glycolysis and glutaminolysis has been shown to be important not only to fulfill the energy requirements of the activated effector CD8 cells but also to provide the biosynthetic materials needed for this rapidly expanding population. Research into the immunometabolics of CD8 cells not only expands our understanding about $\mathrm{CD} 8 \mathrm{~T}$ cells but also provides new pharmaceutical targets that could help to reduce the negative effect of these cells in an allograft immune response.

\section{ACKNOWLEDGMENTS}

The International Fellowship Grant from ProGreffe Fondation supports MY. This work was realized in the context of the IHU-Cesti project which received French government financial support managed by the National Research Agency via the "Investment into the Future" program ANR-10-IBHU-005. The IHU-Cesti project is also supported by Nantes Metropole and the Pays de la Loire Region. This work was realized in the context of the LabEX IGO program supported by the National Research Agency via the investment of the future program ANR-11-LABX-0016-01.

6. Gaber T, Strehl C, Sawitzki B, Hoff P, Buttgereit F. Cellular energy metabolism in T-lymphocytes. Int Rev Immunol (2015) 34(1):34-49. doi:10.3109/088301 85.2014.956358

7. Bental M, Deutsch C. Metabolic changes in activated T cells: an NMR study of human peripheral blood lymphocytes. Magn Reson Med (1993) 29(3):317-26. doi:10.1002/mrm.1910290307

8. Vander Heiden MG, Cantley LC, Thompson CB. Understanding the Warburg effect: the metabolic requirements of cells proliferation. Science (2009) 324(5930):1029-33. doi:10.1126/science.1160809

9. Pollizzi KN, Powell JD. Integrating canonical and metabolic signalling programmes in the regulation of T cell responses. Nat Rev Immunol (2014) 14(7):435-46. doi:10.1038/nri3701

10. Cornell LD, Neal Smith R, Colvin RB. Kidney transplantation: mechanisms of rejection and acceptance. Annu Rev Pathol (2008) 3:189-220. doi:10.1146/ annurev.pathol.3.121806.151508

11. Issa F, Schiopu A, Wood KJ. Role of T cells in graft rejection and transplantation tolerance. Exp Rev Clin Immunol (2010) 6(1):155-69. doi:10.1586/eci.09.64 
12. Bueno V, De Nefrologia D, De Medicina EP. The role of CD8 + T cells during allograft rejection. Braz J Med Biol Res (2002) 35:1247-58. doi:10.1590/ S0100-879X2002001100001

13. Wood KJ, Goto R. Mechanisms of rejection: current perspectives. Transplantation (2012) 93(1):1. doi:10.1097/TP.0b013e31823cab44

14. Robertson H, Wheeler J, Kirby JA, Morley AR. Renal allograft rejection - in situ demonstration of cytotoxic intratubular cells. Transplantation (1996) 61(10):1546-9. doi:10.1097/00007890-199605270-00023

15. Diamond AS, Gill RG. An essential contribution by IFN-gamma to CD8+ $\mathrm{T}$ cell-mediated rejection of pancreatic islet allografts. JImmunol (2000) 165(1):247-55. doi:10.4049/jimmunol.165.1.247

16. Yamada Y, Boskovic S, Aoyama A, Murakami T, Putheti P, Smith RN, et al. Overcoming memory T-cell responses for induction of delayed tolerance in nonhuman primates. Am J Transplant (2012) 12(2):330-40. doi:10.1111/j.1600-6143.2011.03795.x

17. Koyama I, Nadazdin O, Boskovic S, Ochiai T, Smith RN, Sykes M, et al. Depletion of CD8 memory $\mathrm{T}$ cells for induction of tolerance of a previously transplanted kidney allograft. Am J Transplant (2007) 7:1055-61. doi:10.1111/j.1600-6143.2006.01703.x

18. Betjes MG, Meijers RW, de Wit EA, Weimar W, Litjens NH. Terminally differentiated CD8+ Temra cells are associated with the risk for acute kidney allograft rejection. Transplantation (2012) 94(1):63-9. doi:10.1097/ TP.0b013e31825306ff

19. Baeten D, Louis S, Braud C, Braudeau C, Ballet C, MoizantF, et al. Phenotypically and functionally distinct $\mathrm{CD} 8+$ lymphocyte populations in long-term drugfree tolerance and chronic rejection in human kidney graft recipients. J Am Soc Nephrol (2006) 17:294-304. doi:10.1681/ASN.2005020178

20. San Segundo D, Ballesteros MÁ, Naranjo S, Zurbano F, Miñambres E, LópezHoyos M. Increased numbers of circulating CD8 effector memory T cells before transplantation enhance the risk of acute rejection in lung transplant recipients. PLoS One (2013) 8(11):e80601. doi:10.1371/journal.pone.0080601

21. Ordonez L, Bernard I, Chabod M, Augusto JF, Lauwers-Cances V, Cristini C, et al. A higher risk of acute rejection of human kidney allografts can be predicted from the level of CD45RC expressed by the recipients' CD8 T cells. PLoS One (2013) 8(7):e69791. doi:10.1371/journal.pone.0069791

22. Yap M, Boeffard F, Clave E, Pallier A, Danger R, Giral M, et al. Expansion of highly differentiated cytotoxic terminally differentiated effector memory CD8+ T cells in a subset of clinically stable kidney transplant recipients: a potential marker for late graft dysfunction. J Am Soc Nephrol (2014) 25(8):1856-68. doi:10.1681/ASN.2013080848

23. Ligocki AJ, Niederkorn JY. Advances on non-CD4 + Foxp3+ T regulatory cells. Transplantation (2015) 99(8):1. doi:10.1097/TP.0000000000000813

24. Ciubotariu R, Vasilescu R, Ho E, Cinti P, Cancedda C, Poli L, et al. Detection of $\mathrm{T}$ suppressor cells in patients with organ allografts. Hum Immunol (2001) 62(00):15-20. doi:10.1016/S0198-8859(00)00226-3

25. Picarda E, Bézie S, Venturi V, Echasserieau K, Mérieau E, Delhumeau A, et al. MHC-derived allopeptide activates TCR-biased CD8+ tregs and suppresses organ rejection. J Clin Invest (2014) 124(6):2497-512. doi:10.1172/JCI71533

26. Xystrakis E, Dejean AS, Bernard I, Druet P, Liblau R, Gonzalez-Dunia D, et al. Identification of a novel natural regulatory CD8 T-cell subset and analysis of its mechanism of regulation. Blood (2009) 104(10):3294-301. doi:10.1182/ blood-2004-03-1214

27. Suzuki M, Jagger AL, Konya C, Shimojima Y, Pryshchep S, Goronzy JJ, et al. CD8+CD45RA+CCR7+FOXP3+ T cells with immunosuppressive properties: a novel subset of inducible human regulatory T cells. J Immunol (2012) 189(5):2118-30. doi:10.4049/jimmunol.1200122

28. Liu Y, Chen N, Chen G, You P. The protective effect of CD8+CD28- T suppressor cells on the acute rejection responses in rat liver transplantation. Transplant Proc (2007) 39(10):3396-403. doi:10.1016/j.transproceed.2007.06.089

29. Lin YX, Yan LN, Li B, Wang LL, Wen TF, Zeng Y, et al. A significant expansion of CD8+ CD28- T-suppressor cells in adult-to-adult living donor liver transplant recipients. Transplant Proc (2009) 41(10):4229-31. doi:10.1016/j. transproceed.2009.09.072

30. Li XL, Ménoret S, Bezie S, Caron L, Chabannes D, Hill M, et al. Mechanism and localization of CD8 regulatory $\mathrm{T}$ cells in a heart transplant model of tolerance. J Immunol (2010) 185(2):823-33. doi:10.4049/jimmunol.1000120

31. Guppy M, Greiner E, Brand K. The role of the crabtree effect and an endogenous fuel in the energy metabolism of resting and proliferating thymocytes. Eur J Biochem (1993) 212(1):95-9. doi:10.1111/j.1432-1033.1993.tb17637.x
32. Wofford JA, Wieman HL, Jacobs SR, Zhao Y, Rathmell JC. IL-7 promotes Glut1 trafficking and glucose uptake via STAT5-mediated activation of Akt to support T-cell survival. Blood (2008) 111(4):2101-11. doi:10.1182/ blood-2007-06-096297

33. Pallard C, Stegmann AP, van Kleffens T, Smart F, Venkitaraman A, Spits H. Distinct roles of the phosphatidylinositol 3-kinase and STAT5 pathways in IL-7-mediated development of human thymocyte precursors. Immunity (1999) 10(5):525-35. doi:10.1016/S1074-7613(00)80052-7

34. Crawley AM, Vranjkovic A, Faller E, McGuinty M, Busca A, Burke SC, et al. Jak/STAT and PI3K signaling pathways have both common and distinct roles in IL-7-mediated activities in human CD8+ T cells. J Leukoc Biol (2014) 95(1):117-27. doi:10.1189/jlb.0313122

35. Lochner M, Berod L, Sparwasser T. Fatty acid metabolism in the regulation of $\mathrm{T}$ cell function. Trends Immunol (2015) 36(2):81-91. doi:10.1016/j. it.2014.12.005

36. O'Sullivan D, van der Windt GJ, Huang SC, Curtis JD, Chang CH, Buck MD, et al. Memory CD8(+) T cells use cell-intrinsic lipolysis to support the metabolic programming necessary for development. Immunity (2014) 41(1):75-88. doi:10.1016/j.immuni.2014.06.005

37. Pearce EL, Walsh MC, Cejas PJ, Harms GM, Shen H, Wang LS, et al. Enhancing CD8 T-cell memory by modulating fatty acid metabolism. Nature (2009) 460(7251):103-7. doi:10.1038/nature08097

38. Cui G, Staron MM, Gray SM, Ho P-C, Amezquita RA, Wu J, et al. IL-7-induced glycerol transport and TAG synthesis promotes memory CD8(+) T cell longevity. Cell (2015) 161(4):750-61. doi:10.1016/j.cell.2015.03.021

39. Araki K, Turner AP, Shaffer VO, Gangappa S, Keller SA, Bachmann MF. mTOR regulates memory CD8 T-cell differentiation. Nature (2009) 460(7251):108-12. doi:10.1038/nature08155

40. Sipula IJ, Brown NF, Perdomo G. Rapamycin-mediated inhibition of mammalian target of rapamycin in skeletal muscle cells reduces glucose utilization and increases fatty acid oxidation. Metabolism (2006) 55(12):1637-44. doi:10.1016/j.metabol.2006.08.002

41. Xu X, Ye L, Araki K, Ahmed R. MTOR, linking metabolism and immunity. Semin Immunol (2012) 24(6):429-35. doi:10.1016/j.smim.2012.12.005

42. Araki K, Youngblood B, Ahmed R. The role of mTOR in memory CD8+ T-cell differentiation. Immunol Rev (2010) 235(1):234-43. doi:10.1111/j.0105-2896.2010.00898.x

43. Lunt SY, Vander Heiden MG. Aerobic glycolysis: meeting the metabolic requirements of cell proliferation. Annu Rev Cell Dev Biol (2011) 27(1):441-64. doi:10.1146/annurev-cellbio-092910-154237

44. Frauwirth KA, Riley JL, Harris MH, Parry RV, Rathmell JC, Plas DR, et al. The CD28 signaling pathway regulates glucose metabolism. Immunity (2002) 16(6):769-77. doi:10.1016/S1074-7613(02)00323-0

45. Jacobs SR, Herman CE, Maciver NJ, Wofford JA, Wieman HL, Hammen JJ, et al. Glucose uptake is limiting in T cell activation and requires CD28mediated Akt-dependent and independent pathways. JImmunol (2008) 180(7):4476-86. doi:10.4049/jimmunol.180.7.4476

46. Parry RV, Reif K, Smith G, Sansom DM, Hemmings BA, Ward SG. Ligation of the $\mathrm{T}$ cell co-stimulatory receptor $\mathrm{CD} 28$ activates the serine-threonine protein kinase protein kinase B. Eur J Immunol (1997) 27(10):2495-501. doi:10.1002/ eji.1830271006

47. Gubser PM, Bantug GR, Razik L, Fischer M, Dimeloe S, Hoenger G, et al. Rapid effector function of memory CD8+ $\mathrm{T}$ cells requires an immediate-early glycolytic switch. Nat Immunol (2013) 14(10):1064-72. doi:10.1038/ni.2687

48. Chang CH, Curtis JD, Maggi LB Jr, Faubert B, Villarino AV, O'Sullivan D, et al. Posttranscriptional control of $\mathrm{T}$ cell effector function by aerobic glycolysis. Cell (2013) 153(6):1239-51. doi:10.1016/j.cell.2013.05.016

49. van der Windt GJ, O'Sullivan D, Everts B, Huang SC, Buck MD, Curtis JD, et al. CD8 memory $\mathrm{T}$ cells have a bioenergetic advantage that underlies their rapid recall ability. Proc Natl Acad Sci U S A (2013) 110(35):14336-41. doi:10.1073/pnas.1221740110

50. Carr EL, Kelman A, Wu GS, Gopaul R, Senkevitch E, Aghvanyan A, et al. Glutamine uptake and metabolism are coordinately regulated by ERK/ MAPK during T lymphocyte activation. J Immunol (2010) 185(2):1037-44. doi:10.4049/jimmunol.0903586

51. van der Windt GJW, Pearce EL. Metabolic switching and fuel choice during T-cell differentiation and memory development. Immunol Rev (2012) 249(1):27-42. doi:10.1111/j.1600-065X.2012.01150.x 
52. Wasinski F, Gregnani MF, Ornellas FH, Bacurau AV, Câmara NO, Araujo RC. Lymphocyte glucose and glutamine metabolism as targets of the anti-inflammatory and immunomodulatory effects of exercise. Mediators Inflamm (2014) 2014:1-10. doi:10.1155/2014/326803

53. O'Sullivan D, Pearce EL. Targeting T cell metabolism for therapy. Trends Immunol (2015) 36(2):1-10. doi:10.1016/j.it.2014.12.004

54. Cham CM, Gajewski TF. Glucose availability regulates IFN-gamma production and p70S6 kinase activation in CD8+ effector T cells. J Immunol (2005) 174(8):4670-7. doi:10.4049/jimmunol.174.8.4670

55. Sukumar M, Liu J, Ji Y, Subramanian M, Crompton JG, Yu Z, et al. Inhibiting glycolytic metabolism enhances CD8+ T cell memory and antitumor function. J Clin Invest (2013) 123(10):4479-88. doi:10.1172/JCI69589

56. Wang R, Dillon CP, Shi LZ, Milasta S, Carter R, Finkelstein D, et al. The transcription factor myc controls metabolic reprogramming upon $\mathrm{T}$ lymphocyte activation. Immunity (2011) 35(6):871-82. doi:10.1016/j. immuni.2011.09.021

57. Sinclair LV, Rolf J, Emslie E, Shi YB, Taylor PM, Cantrell DA. Control of amino-acid transport by antigen receptors coordinates the metabolic reprogramming essential for T cell differentiation. Nat Immunol (2013) 14(5):500-8. doi:10.1038/ni.2556

58. Singer K, Kastenberger M, Gottfried E, Hammerschmied CG, Büttner M, Aigner $\mathrm{M}$, et al. Warburg phenotype in renal cell carcinoma: high expression of glucose-transporter 1 (GLUT-1) correlates with low CD8+ T-cell infiltration in the tumor. Int J Cancer (2011) 128(9):2085-95. doi:10.1002/ijc.25543

59. Anastasiou D, Poulogiannis G, Asara JM, Boxer MB, Jiang JK, Shen M, et al. Inhibition of pyruvate kinase M2 by reactive oxygen species contributes to cellular antioxidant responses. Science (2011) 334(6060):1278-83. doi:10.1126/ science.1211485.Inhibition

60. Macintyre AN, Gerriets VA, Nichols AG, Michalek RD, Rudolph MC, Deoliveira D, et al. The glucose transporter Glut1 is selectively essential for CD4 T cell activation and effector function. Cell Metab (2014) 20(1):61-72. doi:10.1016/j.cmet.2014.05.004

61. Korn T, Magnus T, Toyka K, Jung S. Modulation of effector cell functions in experimental autoimmune encephalomyelitis by leflunomide - mechanisms independent of pyrimidine depletion. J Leukoc Biol (2004) 76(5):950-60. doi:10.1189/jlb.0504308

62. O'Connor P, Wolinsky JS, Confavreux C, Comi G, Kappos L, Olsson TP, et al. Randomized trial of oral teriflunomide for relapsing multiple sclerosis. N Engl J Med (2011) 365(14):1293-303. doi:10.1056/NEJMoa1014656

63. Le Texier L, Thebault P, Lavault A, Usal C, Merieau E, Quillard T, et al. Long-term allograft tolerance is characterized by the accumulation of $\mathrm{B}$ cells exhibiting an inhibited profile. Am J Transplant (2011) 11(3):429-38. doi:10.1111/j.1600-6143.2010.03336.x

64. Blagih J, Coulombe F, Vincent EE, Dupuy F, Galicia-Vázquez G, Yurchenko E, et al. The energy sensor AMPK regulates $\mathrm{T}$ cell metabolic adaptation and effector responses in vivo. Immunity (2015) 42(1):41-54. doi:10.1016/j. immuni.2014.12.030

65. Yin Y, Choi SC, Xu Z, Perry DJ, Seay H, Croker BP, et al. Normalization of CD4 + T cell metabolism reverses lupus. Sci Transl Med (2015) 7(274):1-13. doi:10.1126/scitranslmed.aaa0835

66. Frauwirth KA, Thompson CB. Regulation of T lymphocyte metabolism. J Immunol (2004) 172(8):4661-5. doi:10.4049/jimmunol.172.8.4661

67. Mary C, Coulon F, Poirier N, Dilek N, Martinet B, Blancho G, et al. Antagonist properties of monoclonal antibodies targeting human CD28. MAbs (2013) 5(1):47-55. doi:10.4161/mabs.22697

68. Poirier N, Mary C, Dilek N, Hervouet J, Minault D, Blancho G, et al. Preclinical efficacy and immunological safety of FR104, an antagonist anti-CD28 monovalent fab' antibody. Am J Transplant (2012) 12(10):2630-40. doi:10.1111/j.1600-6143.2012.04164.x

69. Poirier N, Dilek N, Mary C, Ville S, Coulon F, Branchereau J, et al. FR104, an antagonist anti-CD28 monovalent fab' antibody, prevents alloimmunization and allows calcineurin inhibitor minimization in nonhuman primate renal allograft. Am J Transplant (2015) 15(1):88-100. doi:10.1111/ajt.12964

70. Alexander W. Inhibiting the Akt pathway in cancer treatment: three leading candidates. $P$ T (2011) 36(4):225-7.
71. Abu Eid R, Friedman KM, Mkrtichyan M, Walens A, King W, Janik J, et al. Akt1 and -2 inhibition diminishes terminal differentiation and enhances central memory CD8 + T-cell proliferation and survival. OncoImmunology (2015) 4(5):e1005448. doi:10.1080/2162402X.2015.1005448

72. Zhao X, Guan J-L. Focal adhesion kinase and its signaling pathways in cell migration and angiogenesis. Adv Drug Deliv Rev (2011) 63(8):610-5. doi:10.1016/j.addr.2010.11.001

73. Crompton BD, Carlton AL, Thorner AR, Christie AL, Du J, Calicchio ML, et al. High-throughput tyrosine kinase activity profiling identifies FAK as a candidate therapeutic target in Ewing sarcoma. Cancer Res (2013) 73(9):2873-83. doi:10.1158/0008-5472.CAN-12-1944

74. van der Waart AB, van de Weem NM, Maas F, Kramer CS, Kester MG, Falkenburg JH, et al. Inhibition of Akt signaling promotes the generation of superior tumor-reactive T cells for adoptive immunotherapy. Blood (2014) 124(23):3490-500. doi:10.1182/blood-2014-05-578583

75. Edozie FC, Nova-Lamperti EA, Povoleri GA, Scottà C, John S, Lombardi G, et al. Regulatory T-cell therapy in the induction of transplant tolerance: the issue of subpopulations. Transplantation (2014) 98(4):370-9. doi:10.1097/ TP.0000000000000243

76. Heitman J, Movva NR, Hall MN. Targets for cell cycle arrest by the immunosuppressant rapamycin in yeast. Science (1991) 253(5022):905-9. doi:10.1126/ science. 1715094

77. Brown EJ, Albers MW, Shin TB, Ichikawa K, Keith CT, Lane WS, et al. A mammalian protein targeted by G1-arresting rapamycin-receptor complex. Nature (1994) 369(6483):756-8. doi:10.1038/369756a0

78. Laplante M, Sabatini DM. mTOR signaling at a glance. J Cell Sci (2009) 122(Pt 20):3589-94. doi:10.1242/jcs.051011

79. Laplante M, Sabatini DM. Regulation of mTORC1 and its impact on gene expression at a glance. J Cell Sci (2013) 126(Pt 8):1713-9. doi:10.1242/ jcs. 125773

80. DeBerardinis RJ, Lum JJ, Thompson CB. Phosphatidylinositol 3-kinase-dependent modulation of carnitine palmitoyltransferase $1 \mathrm{~A}$ expression regulates lipid metabolism during hematopoietic cell growth. J Biol Chem (2006) 281(49):37372-80. doi:10.1074/jbc.M608372200

81. Porstmann T, Santos CR, Griffiths B, Cully M, Wu M, Leevers S, et al. SREBP activity is regulated by mTORC1 and contributes to Akt-dependent cell growth. Cell Metab (2008) 8(3):224-36. doi:10.1016/j.cmet.2008.07.007

82. Sehgal SN. Sirolimus: its discovery, biological properties, and mechanism of action. Transplant Proc (2003) 35(3):S7-14. doi:10.1016/ S0041-1345(03)00211-2

83. Halloran PF. Immunosuppressive drugs for kidney transplantation. N Engl J Med (2004) 351:2715-30. doi:10.1056/NEJMra033540

84. Battaglia M, Stabilini A, Migliavacca B, Horejs-Hoeck J, Kaupper T, Roncarolo MG. Rapamycin promotes expansion of functional CD4+CD25+FOXP3+ regulatory $\mathrm{T}$ cells of both healthy subjects and type 1 diabetic patients. J Immunol (2006) 177(12):8338-47. doi:10.4049/jimmunol.177.12.8338

85. El Essawy B, Putheti P, Gao W, Strom TB. Rapamycin generates graft-homing murine suppressor $\mathrm{CD} 8+\mathrm{T}$ cells that confer donor-specific graft protection. Cell Transplant (2011) 20:1759-69. doi:10.1016/j.biotechadv.2011.08.021. Secreted

86. Barbon CM, Davies JK, Voskertchian A, Kelner RH, Brennan LL, Nadler $\mathrm{LM}$, et al. Alloanergization of human T cells results in expansion of alloantigen-specific CD8(+) CD28(-) suppressor cells. Am J Transplant (2014) 14:305-18. doi:10.1111/ajt.12575

Conflict of Interest Statement: The authors declare that the research was conducted in the absence of any commercial or financial relationships that could be construed as a potential conflict of interest.

Copyright () 2015 Yap, Brouard, Pecqueur and Degauque. This is an open-access article distributed under the terms of the Creative Commons Attribution License (CC $B Y)$. The use, distribution or reproduction in other forums is permitted, provided the original author(s) or licensor are credited and that the original publication in this journal is cited, in accordance with accepted academic practice. No use, distribution or reproduction is permitted which does not comply with these terms. 